\title{
The Role of MTHFR Genotype in Colorectal Cancer Susceptibility in Taiwan
}

\author{
KUEI-MAN LIN ${ }^{1,2}$, MEI-DUE YANG ${ }^{3}$, CHIA-WEN TSAI $^{3}$, WEN-SHIN CHANG ${ }^{3}$, CHIEH-LUN HSIAO ${ }^{3}$, \\ LONG-BIN JENG ${ }^{3}$, TE-CHENG YUEH ${ }^{4,5^{*}}$, MENG-CHIH LEE ${ }^{1,6,7^{*}}$ and DA-TIAN BAU ${ }^{3,8^{*}}$ \\ ${ }^{1}$ Institute of Medicine, Chung Shan Medical University, Taichung, Taiwan, R.O.C.; \\ ${ }^{2}$ Department of Nursing, Hungkuang University, Taichung, Taiwan, R.O.C.; \\ ${ }^{3}$ Terry Fox Cancer Research Laboratory, Translational Medical Research Center, \\ China Medical University Hospital, Taichung, Taiwan, R.O.C.; \\ ${ }^{4}$ Taichung Armed Forces General Hospital, Taichung, Taiwan, R.O.C.; \\ ${ }^{5}$ National Defense Medical Center, Taipei, Taiwan, R.O.C.; \\ ${ }^{6}$ Department of Family Medicine, Taichung Hospital, Ministry of Health and Welfare, Taichung, Taiwan, R.O.C.; \\ ${ }^{7}$ Institute of Population Health Sciences, National Health Research Institutes, Miaoli, Taiwan, R.O.C.; \\ ${ }^{8}$ Department of Bioinformatics and Medical Engineering, Asia University, Taichung, Taiwan, R.O.C.
}

\begin{abstract}
Aim: To evaluate the contribution of methylenetetrahydrofolate reductase (MTHFR) genotype to the risk of colorectal cancer (CRC) in Taiwan. Materials and Methods: In this hospital-based case-control study, the role of MTHFR C677T (rs1801133) and A1298C (rs1801131) genotypes in determining CRC risk were investigated among 362 patients with CRC and an equal number of age-and gender-matched healthy individuals. Results: The percentages of CC, CT and TT genotypes for MTHFR rs 1801133 were $64.1 \%, 29.8 \%$ and $6.1 \%$ in the CRC group and $51.1 \%, 37.0 \%$ and $11.9 \%$ in the control group, respectively ( $p$ for trend=0.0006). Analysis of the allelic frequency distribution showed that the variant $T$ allele of MTHFR rs1801133 conferred a lower CRC susceptibility than did the wild-type $C$ allele (odds ratio $(O R)=0.66,95 \%$ confidence interval $\left.(\mathrm{CI})=0.52-0.84, p=4.32 \times 10^{-5}\right)$. For the gene-lifestyle interaction, there were obvious protective effects of MTHFR rs1801133 T allele on the risk of CRC among non-smokers, ever smokers and non-alcohol drinkers, but not drinkers. Conclusion: MTHFR rs1801133 T allele serves as a predictive marker for CRC risk and future studies
\end{abstract}

*These Authors contributed equally to this study.

Correspondence to: Da-Tian Bau, Terry Fox Cancer Research Laboratory, China Medical University Hospital, 2 Yuh-Der Road, Taichung, 40447 Taiwan, R.O.C. Tel: +886 422053366 (Ext. 5805), e-mail: datian@mail.cmuh.org.tw; artbau2@gmail.com

Key Words: Colorectal cancer, genotype, MTHFR, polymorphism, Taiwan. with larger samples and functional evaluation are warranted to validate the current findings.

Colorectal cancer (CRC) incidence and mortality are both third among cancer patients worldwide global and are expected to increase by $60 \%$ to more than 2.2 million new cases and 1.1 million deaths by $2030(1,2)$. For many years, the incidence and mortality of CRC has occupied the first and third ranks among the most common types of cancer in Taiwan $(3,4)$. Etiological studies have attributed more than $85 \%$ of CRC risk to lifestyle and environmental factors, particularly meat consumption, cigarette smoking, and exposure to carcinogenic aromatic amines $(5,6)$. From the viewpoint of epidemiology, about $15-20 \%$ of CRC cases have a strong familial history of cancer that have led epidemiologists to seek additional inherited susceptibility factors (7-9). In Taiwan, although specific biomarkers for CRC prediction and detection have been reported in the past decade $(4,10)$, novel genomic markers of CRC and the interactions among the genomic, lifestyle and environmental risk factors are still of high interest and largely unrevealed.

The protein methylenetetrahydrofolate reductase (MTHFR) is an enzyme in charge of the conversion of 5,10methylene-tetrahydrofolate into 5-methyltetrahydrofolate, homocysteine re-methylation, and neosynthesis of DNA and RNA (11). The multi-aspect regulatory effects of MTHFR on DNA methylation, DNA replication, DNA repair and cell division make it a potential cancer-predisposing gene. It is reasonable that rapidly proliferating malignancies have a higher requirement for DNA neosynthesis and cell division and could be more susceptible to folate deficiency, resulting in an instable genome with more DNA damage. In a BALB/c 
mouse model, low dietary folate and MTHFR deficiency induced the formation of intestinal tumors (12).

The most subtle genetic variations are single nucleotide polymorphisms (SNPs) which determine personal susceptibility to human diseases, such as cancer. In literature, populationbased investigations of MTHFR variations have focused on examining the genotypes of two SNPs of a catalytic domain, C677T (rs1801133) and A1298C (rs1801131), which may determine the enzymatic activity of encoded $\operatorname{MTHFR}(13,14)$. In the case of the MTHFR C677T polymorphism, the cytosine base at position 677 changes to a thymidine base, which in turn affects the amino acid at position 222, as it is changed from alanine to valine. The resultant MTHFR enzyme from the TT variant becomes thermolabile, resulting in decreased activity with elevated temperature (15). The modified protein loses its flavin adenine dinucleotide cofactor more quickly and has a lower stability than the enzyme encoded by CC. The thermolabile effect on TT-encoded MTHFR can be suppressed by the addition of folate, which causes a higher affinity for flavin adenine dinucleotide and an increase in MTHFR stability (15). The second polymorphism, MTHFR A1298C, is located in the coding regulatory domain (16). It was reported that enzyme activity of heterozygotes and rare homozygotes of MTHFR C677T variant was only $60 \%$ and $30 \%$, respectively, of the wild-type (14); for MTHFR A1298C, the rare homozygotes have $60 \%$ of wild-type activity (14). In 2004, it was reported that colon and breast cancer cells with MTHFR $677 \mathrm{~T}$ variant had lower MTHFR activity than those with MTHFR 677C (17). In addition, mutant MTHFR 677T increased the sensitivity of cancer cells to the cytotoxicity of 5-fluorouracil (5-FU) (17). In null mouse experiments, the expression of MTHFR $677 \mathrm{~T}$ enhanced the growth rates of xenografts compared to those expressing wild-type MTHFR 677C. Furthermore, consistent with the evidence from cell models, the $677 \mathrm{~T}$ xenografts were also more sensitive to 5-FU treatment than those of $677 \mathrm{C}$ in a mouse model (17). Many studies investigating MTHFR genetic variants have found positive associations with various types of cancer, such as of breast $(18,19)$, oral $(20,21)$, lung $(22)$ and prostate $(23)$ cancer and leukemia (24).

In this study, we analyzed the genetic polymorphisms of both MTHFR C677T and A1298C using representative CRC samples (control/case $=362 / 362$ ) in order to examine the association between MTHFR genotypes and CRC in a Taiwanese population, and summarize the relevant and updated literature about CRC and MTHFR genotypes.

\section{Materials and Methods}

Investigated population. The investigated population included 724 individuals (362 patients with CRC and 362 controls). Patients diagnosed with CRC were recruited at the outpatient clinics of general surgery at the China Medical University Hospital, Taichung, Taiwan by the team of Drs. LB Jeng and MD Yang. The clinical
Table I. Summary of basic and clinical data of the 362 patients with colorectal cancer and 362 matched non-cancer healthy controls.

\begin{tabular}{|c|c|c|c|c|c|}
\hline \multirow[b]{2}{*}{ Characteristic } & \multicolumn{2}{|c|}{$\begin{array}{l}\text { Controls } \\
(\mathrm{n}=362)\end{array}$} & \multicolumn{2}{|c|}{$\begin{array}{c}\text { Cases } \\
(\mathrm{n}=362)\end{array}$} & \multirow[b]{2}{*}{$p$-Value ${ }^{\mathrm{a}}$} \\
\hline & $\mathrm{n}$ & $\%$ & $\mathrm{n}$ & $\%$ & \\
\hline \multicolumn{6}{|l|}{ Age (years) } \\
\hline$\leq 60$ & 93 & $25.7 \%$ & 95 & $26.2 \%$ & \\
\hline$>60$ & 269 & $74.3 \%$ & 267 & $73.8 \%$ & 0.8654 \\
\hline \multicolumn{6}{|l|}{ Gender } \\
\hline Male & 209 & $57.7 \%$ & 203 & $56.1 \%$ & \\
\hline Female & 153 & $42.3 \%$ & 159 & $43.9 \%$ & 0.6525 \\
\hline \multicolumn{6}{|l|}{ Smoking } \\
\hline Non-smoker & 278 & $76.8 \%$ & 271 & $74.9 \%$ & \\
\hline Smoker & 84 & $23.2 \%$ & 91 & $25.1 \%$ & 0.6525 \\
\hline \multicolumn{6}{|l|}{ Drinking } \\
\hline Non-drinker & 311 & $85.9 \%$ & 318 & $87.8 \%$ & \\
\hline Drinker & 51 & $14.1 \%$ & 44 & $12.2 \%$ & 0.4410 \\
\hline \multicolumn{6}{|c|}{ Tumor size $(\mathrm{cm})$} \\
\hline$<5$ & & & 195 & $53.9 \%$ & \\
\hline$\geq 5$ & & & 167 & $46.1 \%$ & \\
\hline \multicolumn{6}{|l|}{ Location } \\
\hline Colon & & & 257 & $71.0 \%$ & \\
\hline Rectum & & & 105 & $29.0 \%$ & \\
\hline \multicolumn{6}{|c|}{ Lymph node metastasis } \\
\hline Negative & & & 210 & $58.0 \%$ & \\
\hline Positive & & & 152 & $42.0 \%$ & \\
\hline
\end{tabular}

SD, Standard deviation. 'Based on chi-square test without Yates' correction.

characteristics of patients, including histological details, were all graded and defined by expert surgeons as previous published (4, 10). All participants completed a self-administered questionnaire and provided a 5-ml sample of peripheral blood for genotyping. An equal number of non-cancer healthy volunteers $(n=362)$ were selected as controls by matching for age, gender and some indulgences after initial random sampling from the Health Examination Cohort of the Hospital with the help of colleagues in the Department of Family Medicine. The exclusion criteria for the control group included previous malignancy, metastasized cancer from other or unknown origin and any familial or genetic diseases. This study was approved by the Institutional Review Board of the China Medical University Hospital (IRB project identification coding number: DMR99-IRB-108) and written informed consent was obtained from all participants with the help of Tissue Bank of China Medical University Hospital. Selected patient characteristics extracted from personal questionnaires is summarized in Table I.

Genotyping conditions. The genomic DNA from peripheral blood leucocytes of each recruited subject was prepared with the QIAamp Blood Mini Kit (Blossom, Taipei, Taiwan) and stored at $-80^{\circ} \mathrm{C}$ until processed as per our recent publications (25-28). The methodology for MTHFR C677T (rs1801133) and A1298C (rs1801131) genotyping, including the designing of the specific primers and the selection of restriction enzymes, were performed at the Terry Fox Cancer Research Laboratory. Briefly, the sequences for forward and reverse primer pairs for MTHFR C677T were: forward 5'-TGA AGG AGA AGG TGT CTG 
Table II. Distribution of methylenetetrahydrofolate reductase (MTHFR) genotypes among the 362 patients with colorectal cancer and 362 matched healthy controls.

\begin{tabular}{|c|c|c|c|c|c|c|}
\hline \multirow[t]{2}{*}{ Genotype } & \multicolumn{2}{|c|}{ Controls } & \multicolumn{2}{|c|}{ Patients } & \multirow[t]{2}{*}{ OR $(95 \% \mathrm{CI})$} & \multirow[t]{2}{*}{$p$-Value ${ }^{\mathrm{a}}$} \\
\hline & $\mathrm{n}$ & $\%$ & $\mathrm{n}$ & $\%$ & & \\
\hline \multicolumn{7}{|c|}{ C677T rs1801133 } \\
\hline $\mathrm{CC}$ & 185 & $51.1 \%$ & 232 & $64.1 \%$ & 1.00 (Reference) & \\
\hline $\mathrm{CT}$ & 134 & $37.0 \%$ & 108 & $29.8 \%$ & $0.64(0.47-0.88)$ & $0.0064 *$ \\
\hline TT & 43 & $11.9 \%$ & 22 & $6.1 \%$ & $0.41(0.24-0.71)$ & $0.0011^{*}$ \\
\hline$p_{\text {trend }}$ & & & & & & $0.0006^{*}$ \\
\hline \multicolumn{7}{|c|}{ Carrier comparison } \\
\hline $\mathrm{CC}+\mathrm{CT}$ & 319 & $88.1 \%$ & 340 & $93.9 \%$ & 1.00 (Reference) & \\
\hline $\mathrm{TT}$ & 43 & $11.9 \%$ & 22 & $6.1 \%$ & $0.48(0.28-0.82)$ & $0.0063 *$ \\
\hline $\mathrm{CC}$ & 185 & $51.1 \%$ & 232 & $64.1 \%$ & 1.00 (Reference) & \\
\hline $\mathrm{CT}+\mathrm{TT}$ & 179 & $48.9 \%$ & 130 & $35.9 \%$ & $0.58(0.43-0.78)$ & $0.0003 *$ \\
\hline \multicolumn{7}{|c|}{ A1298C rs1801131 } \\
\hline AA & 233 & $64.4 \%$ & 228 & $63.0 \%$ & 1.00 (Reference) & \\
\hline $\mathrm{AC}$ & 111 & $30.6 \%$ & 117 & $32.3 \%$ & $1.08(0.78-1.48)$ & 0.6462 \\
\hline $\mathrm{CC}$ & 18 & $5.0 \%$ & 17 & $4.7 \%$ & $0.97(0.49-1.92)$ & 0.9195 \\
\hline$p_{\text {trend }}$ & & & & & & 0.8866 \\
\hline \multicolumn{7}{|c|}{$\begin{array}{l}\text { Carrier } \\
\text { comparison }\end{array}$} \\
\hline $\mathrm{AA}+\mathrm{AC}$ & 344 & $95.0 \%$ & 345 & $95.3 \%$ & 1.00 (Reference) & \\
\hline $\mathrm{CC}$ & 18 & $5.0 \%$ & 17 & $4.7 \%$ & $0.94(0.48-1.86)$ & 0.8624 \\
\hline AA & 233 & $64.4 \%$ & 228 & $63.0 \%$ & 1.00 (Reference) & \\
\hline $\mathrm{AC}+\mathrm{CC}$ & 129 & $35.6 \%$ & 134 & $37.0 \%$ & $1.06(0.78-1.44)$ & 0.6992 \\
\hline
\end{tabular}

OR, Odds ratio; CI, confidence interval. aBased on Chi-square test without Yates' correction; *statistically significant.

Table III. Distribution of allelic frequencies for methylenetetrahydrofolate reductase (MTHFR) among the 362 patients with colorectal cancer and 362 matched healthy controls.

\begin{tabular}{|c|c|c|c|c|c|c|}
\hline Allele & Controls, $\mathrm{n}$ & $\%$ & Cancer patients, $\mathrm{n}$ & $\%$ & OR $(95 \% \mathrm{CI})$ & $p$-Value ${ }^{\mathrm{a}}$ \\
\hline \multicolumn{7}{|c|}{ C677T rs1801133 } \\
\hline $\mathrm{C}$ & 504 & $69.6 \%$ & 572 & $79.0 \%$ & 1.00 (Reference) & \\
\hline $\mathrm{T}$ & 202 & $30.4 \%$ & 152 & $21.0 \%$ & $0.66(0.52-0.84)$ & $4.32 \times 10^{-5^{*}}$ \\
\hline \multicolumn{7}{|c|}{ A1298C rs1801131 } \\
\hline A & 577 & $79.7 \%$ & 573 & $79.1 \%$ & 1.00 (Reference) & \\
\hline $\mathrm{C}$ & 147 & $20.3 \%$ & 151 & $20.9 \%$ & $1.03(0.80-1.33)$ & 0.7949 \\
\hline
\end{tabular}

aBased on Chi-square test without Yates' correction; *statistically significant.

CGG GA-3' and reverse 5'-AGG ACG GTG CGG TGA GAG TG-3' The primers for MTHFR A1298C were: forward 5'- GGG AGG AGC TGA CCA GTG CAG-3' and reverse 5'-GGG GTC AGG CCA GGG GCA G-3'. The following cycling conditions were performed: 5 min of initial denaturation at $95^{\circ} \mathrm{C}, 35$ cycles of $30 \mathrm{~s}$ of denaturation at $95^{\circ} \mathrm{C}$, $30 \mathrm{~s}$ of annealing at $54^{\circ} \mathrm{C}$ and $1 \mathrm{~min}$ of elongation at $72^{\circ} \mathrm{C}$, and $7 \mathrm{~min}$ of final extension at $72^{\circ} \mathrm{C}$. The 198-bp polymerase chain reaction (PCR) product of MTHFR C677T and 138-bp PCR product of MTHFR A1298C were subject to enzyme digestion with Hinf I and Fnu4H I (New England Biolabs, Beverly, MA, USA), respectively for $4 \mathrm{~h}$ and then visualized by ethidium bromide-stained 3\% agarose gel electrophoresis under UV light. On digestion with Hinf I, the PCR product of MTHFR C677T arising from the $\mathrm{C}$ allele was uncut (198 bp), whereas the $\mathrm{T}$ allele was cut into fragments of $175 \mathrm{bp}$ and $23 \mathrm{bp}$. On digestion with Fnu4H I, the PCR product of MTHFR A1298C arising from the A allele was uncut ( $138 \mathrm{bp}$ ), whereas the $\mathrm{C}$ allele was cut into fragments of $119 \mathrm{bp}$ and $19 \mathrm{bp}$. All the genotypic processing was repeated by two researchers independently and blindly; all the genotyping results were $100 \%$ concordant.

Statistical analyses. Student's $t$-test was applied for the comparison of ages between the CRC case and the control groups. Pearson's chi-square test was applied to compare the distribution of the MTHFR genotypes among the subgroups. The associations between the MTHFR genotypes and CRC risk were estimated by computing odds ratios (ORs) and related $95 \%$ confidence intervals (CIs) from logistic regression analysis. Statistically, any difference at $p<0.05$ was taken as being significant between the two groups compared. 
Table IV. Odds ratios for methylenetetrahydrofolate reductase (MTHFR) C677T rs1801133 genotype and colorectal cancer risk after stratification by smoking status.

\begin{tabular}{|c|c|c|c|c|c|c|c|c|c|c|}
\hline \multirow[t]{2}{*}{ Genotype } & \multicolumn{2}{|c|}{ Non-smokers, $\mathrm{n}$} & \multirow[t]{2}{*}{ OR $(95 \% \mathrm{CI})^{\mathrm{a}}$} & \multirow[t]{2}{*}{$\mathrm{aOR}(95 \% \mathrm{CI})^{\mathrm{b}}$} & \multirow[t]{2}{*}{$p$-Value } & \multicolumn{2}{|c|}{ Smokers, $\mathrm{n}$} & \multirow[t]{2}{*}{ OR $(95 \% \mathrm{CI})^{\mathrm{a}}$} & \multirow[t]{2}{*}{$\mathrm{aOR}(95 \% \mathrm{CI})^{\mathrm{b}}$} & \multirow[t]{2}{*}{$p$-Value } \\
\hline & Controls & Cases & & & & Controls & Cases & & & \\
\hline $\mathrm{CC}$ & 144 & 167 & 1.00 (ref) & 1.00 (ref) & & 41 & 65 & 1.00 (ref) & 1.00 (ref) & \\
\hline CT & 102 & 86 & $0.73(0.51-1.05)$ & $0.75(0.50-1.11)$ & 0.0851 & 32 & 22 & $0.43(0.22-0.85)$ & $0.47(0.31-0.87)$ & $0.0135^{*}$ \\
\hline TT & 32 & 18 & $0.49(0.26-0.90)$ & $0.52(0.33-0.88)$ & $0.0201^{*}$ & 11 & 4 & $0.23(0.07-0.77)$ & $0.31(0.14-0.73)$ & $0.0112 *$ \\
\hline Total & 278 & 271 & & & & 84 & 91 & & & \\
\hline
\end{tabular}

$\mathrm{CI}$, Confidence interval; a $\mathrm{OR}$, adjusted odds ratio. ${ }^{\mathrm{B} B y}$ multivariate logistic regression analysis; by multivariate logistic regression analysis after adjusting for age, gender and alcohol drinking status; *statistically significant.

Table V. Odds ratios for methylenetetrahydrofolate reductase (MTHFR) rs 1801133 genotype and risk of colorectal cancer risk after stratification by alcohol drinking status.

\begin{tabular}{|c|c|c|c|c|c|c|c|c|c|c|}
\hline \multirow[t]{2}{*}{ Genotype } & \multicolumn{2}{|c|}{ Non-drinker, $\mathrm{n}$} & \multirow[t]{2}{*}{ OR $(95 \% \mathrm{CI})^{\mathrm{a}}$} & \multirow[t]{2}{*}{$\mathrm{aOR}(95 \% \mathrm{CI})^{\mathrm{b}}$} & \multirow[t]{2}{*}{$p$-Value } & \multicolumn{2}{|c|}{ Drinkers, $\mathrm{n}$} & \multirow[t]{2}{*}{ OR $(95 \% \mathrm{CI})^{\mathrm{a}}$} & \multirow[t]{2}{*}{$\mathrm{aOR}(95 \% \mathrm{CI})^{\mathrm{b}}$} & \multirow[t]{2}{*}{$p$-Value } \\
\hline & Controls & Cases & & & & Controls & Cases & & & \\
\hline $\mathrm{CC}$ & 163 & 203 & 1.00 (ref) & 1.00 (ref) & & 22 & 29 & 1.00 (ref) & 1.00 (ref) & \\
\hline $\mathrm{CT}$ & 111 & 95 & $0.69(0.49-0.97)$ & $0.73(0.54-0.93)$ & $0.0317 *$ & 23 & 13 & $0.43(0.18-1.03)$ & $0.41(0.21-1.01)$ & 0.0564 \\
\hline $\mathrm{TT}$ & 37 & 20 & $0.43(0.24-0.78)$ & $0.48(0.33-0.74)$ & $0.0042 *$ & 6 & 2 & $0.25(0.05-1.38)$ & $0.33(0.11-1.21)$ & 0.0934 \\
\hline Total & 311 & 318 & & & & 51 & 44 & & & \\
\hline
\end{tabular}

$\mathrm{CI}$, Confidence interval; aOR, adjusted odds ratio. ${ }^{a}$ By multivariate logistic regression analysis; by multivariate logistic regression analysis after adjusting for age, gender and smoking status; *statistically significant.

\section{Results}

The frequency distribution of selected basic characters, including age, gender, smoking and alcohol drinking statuses for the 362 patients with CRC in the case group and 362 noncancer healthy participants of the control group are summarized and compared in Table I. In addition, clinical characters include tumor size, location, and lymph node metastasis status of the patients are also summarized in Table I. Since we applied frequency matching to recruit non-cancer healthy individuals as controls, there was no difference in the distribution of age or gender between the control and case groups $(p=0.8654$ and 0.6525 , respectively) (Table I). There was no difference in the distribution of smoking or drinking subpopulations between the control and case groups ( $p=0.6525$ and 0.4410 , respectively). There were 195 and 167 patients with tumor size $<5 \mathrm{~cm}$ and $\geq 5$ $\mathrm{cm}$, respectively. Tumor was located in the colon in 257 patients and in the rectum in 105 . There were 152 patients with and 210 without lymph node metastasis (Table I).

The distribution of MTHFR C677T and A1298C genotypes among the 326 non-cancer controls and the 326 patients with $\mathrm{CRC}$ are presented and statistically analyzed in Table II. The results showed that the genotypes of MTHFR C677T were significantly differently distributed between case and control groups ( $p$ for trend $=0.0006$ ) (Table II). In detail, the MTHFR
C677T the heterozygous CT and homozygous TT were associated with lower CRC risk than the wild-type CC genotype ( $p=0.0064$ and 0.0011 , respectively; Table II). In the recessive model, there was a significant association between the TT genotype of MTHFR C677T and CRC risk, compared with $\mathrm{CC}+\mathrm{CT}$ genotypes ( $p=0.0063$; Table II). In the dominant model, there was also a significant association between the $\mathrm{CC}$ genotype of MTHFR C677T and CRC risk, compared with CT+TT genotypes ( $p=0.0003$; Table II). The genotypes of MTHFR A1298C were not differentially distributed between case and control groups in any model (Table II).

To confirm the results shown in Table II, analysis of allelic frequency distribution for the MTHFR C677T and A1298C SNPs was further conducted and the results are presented in Table III. Supporting the findings that genotype of MTHFR C677T was associated with CRC risk, the variant allele $\mathrm{T}$ was found at a frequency of $21.0 \%$ in the patient group, significantly lower than that of $30.4 \%$ in the non-cancer healthy control group ( $p=4.32 \times 10^{-5}$, Table III). On the contrary, there was no significant difference in the allelic frequencies of MTHFR A1298C between the case and control groups (Table III).

Since smoking and alcohol drinking habits are well-known risk factors for CRC in Taiwan, we were interested in investigating the interactions between the novel genetic marker of MTHFR C677T and personal cigarette smoking and alcohol 
drinking habits. Among non-smokers, those with TT genotype at MTHFR C677T were at 0.49 -fold odds of having CRC $(p=0.0201)$, conferring a protective effect, compared with those with CC genotype (Table IV). After adjusting for age, gender and alcohol drinking status, statistical significance still existed at a similar level ( $p=0.0112$; Table IV). The protective effects are very similar to those with CT and TT at MTHFR C677T among smokers (Table IV). On the other hand, among nondrinkers, those with CT and TT genotypes at MTHFR C677T were at 0.69 and 0.43 -fold odds of having CRC ( $p=0.0317$ and 0.0042 , respectively), conferring a protective effect, while this was not the case for ever drinkers (Table V). After adjusting for age, gender and smoking status, results were equally significant (Table V).

\section{Discussion}

In literature, the genotypes of MTHFR may be associated with prognosis of chemotherapy in patients with CRC (29). Similar to the report of Robien and colleagues mentioned in the introduction, people carrying the common T variant of MTHFR genotypes have reduced MTHFR enzyme activity, 50\% that of normal, with subsequently increased plasma homocysteine concentrations (30). The first study to evaluate the association between MTHFR C677T polymorphism and CRC was performed by Chen and colleagues, reporting that the MTHFR C677T variant affected enzyme activity and was involved in abnormal methylation as well as influencing DNA synthesis, leading to colorectal tumorigenesis (31). In 2001, Junker et al. also reported that the MTHFR enzyme activity with the TT and CT genotypes were $30 \%$ and $65 \%$ of that associated with the CC genotype (32). In the present study, the relative percentages of MTHFR C677T taints were all significantly lower in patients with CRC compared with those who were healthy controls; however, such a difference in genotypic distribution was not observed for MTHFR A1298C (Table II). In addition, a lower percentage of individuals bearing the T allele at MTHFR C677T was observed in patient group than that in control group (Table III). Furthermore, the genotypes of MTHFR C677T may conduct its protective influence for both smokers and nonsmokers, and those non-drinkers (Table V).

Despite our efforts to conduct accurate and comprehensive genotyping and related analysis, there are some limitations that should be noted. Firstly, the lack of recorded follow-up limited the analysis of the correlation of prognostic indices, such as survival rates. From the viewpoint of prognosis, $\mathrm{Wu}$ and colleagues found that TT-homozygosity at MTHFR C677T was significantly associated with higher survival rates for patients with CRC $(29,33)$. Secondly, lack of collection of both tumor and non-tumor samples limited the study of differential expression of MTHFR mRNA and protein levels among the participants, in addition to the inter-individual difference of the patients with CRC. Further molecular investigations of the genotype-phenotype correlation may help in understanding the contribution of MTHFR C677T genotype not only to overall cell proliferation, DNA neo-synthesis and DNA repair capacity, but also regarding personal susceptibility to $\mathrm{CRC}$ and other types of cancer. From the viewpoint of folate metabolism, the serum monitoring of folate levels should be taken into consideration by patient care systems since Chiang et al. reported that higher serum folate concentration was significantly correlated with increased CRC risk in individuals with adenomatous polyps, while it had no effect on CRC risk in healthy controls (34). Thirdly, the relatively small sample size, especially in subgroup analysis, such as those shown in Tables IV and V, may have caused bias and reduced the statistic power of our estimates. The strongest evidence supporting our findings comes from meta-analyses showing that MTHFR 677 homozygous mutation TT genotype was revealed to be a protective genotype for CRC with statistical significance in a pooled population (35).

In conclusion, this study provides evidence that the $\mathrm{T}$ allele at MTHFR C677T rs1801133 may serve as a protective factor which interacts with smoking and alcohol habits to determine personal susceptibility to CRC. At the same time, overall monitoring of alterations of cell proliferation, DNA neosynthesis, DNA repair capacity and folate metabolism for each individual according to their MTHFR genotype may help us provide a better quality care and prognosis for patients with CRC.

\section{Acknowledgements}

The Authors declare no conflict of interest in regard to this study. We appreciate Huai-Mei Hsu, Hsin-Ting Li, Shiou-Ting Yen, Su-Yi Pan, Chia-Wen Lin, Cin-Wun Wu and the Tissue Bank of China Medical University Hospital for their excellent technical assistance and all the study participants, doctors, nurses and colleagues. This study was supported mainly by the China Medical University and Hospital to Professor Bau (DMR107-107) and partially by research grants from Taiwan Ministry of Health and Welfare Clinical Trial and Research Center of Excellence (MOHW106-TDU-B-212-113004) and Taichung Armed Forces General Hospital to Dr. Yueh (106A14).

\section{References}

1 Siegel RL, Miller KD, Fedewa SA, Ahnen DJ, Meester RGS, Barzi A and Jemal A: Colorectal cancer statistics, 2017. CA Cancer J Clin 67: 177-193, 2017.

2 Arnold M, Sierra MS, Laversanne M, Soerjomataram I, Jemal A and Bray F: Global patterns and trends in colorectal cancer incidence and mortality. Gut 66: 683-691, 2017.

3 Chou CL, Tseng CJ and Shiue YL: The impact of young age on the prognosis for colorectal cancer: a population-based study in Taiwan. Jpn J Clin Oncol 47: 1010-1018, 2017.

4 Yueh TC, Chou AK, Gong CL, Fu CK, Pei JS, Wu MH, Tsai CW, Chang WS, Hsiao CL, Yen ST, Li HT and Bau DT: The contribution of excision repair cross-complementing group 1 genotypes to colorectal cancer susceptibility in Taiwan. Anticancer Res 37: 2307-2313, 2017. 
5 Rattray NJW, Charkoftaki G, Rattray Z, Hansen JE, Vasiliou V and Johnson CH: Environmental influences in the etiology of colorectal cancer: the premise of metabolomics. Curr Pharmacol Rep 3: 114-125, 2017.

6 Cichoz-Lach H, Szumilo J, Celinski K, Kasztelan-Szczerbinska B, Szczerbinski M, Swatek J, Wronecki L, Wargocki J and Slomka M: Results of screening in Lublin Province, Poland, for colorectal cancer and neoplastic polyps - the role of environmental factors. Ann Agric Environ Med 24: 108-112, 2017.

7 Butterworth AS, Higgins JP and Pharoah P: Relative and absolute risk of colorectal cancer for individuals with a family history: a meta-analysis. Eur J Cancer 42: 216-227, 2006.

8 Houlston RS and Tomlinson IP: Polymorphisms and colorectal tumor risk. Gastroenterology 121: 282-301, 2001.

9 Rasool S, Rasool V, Naqvi T, Ganai BA and Shah BA: Genetic unraveling of colorectal cancer. Tumour Biol 35: 5067-5082, 2014.

10 Chang WS, Yueh TC, Tsai CW, Ji HX, Wu CN, Wang SC, Lai YL, Hsu SW, Hsieh MH, Hsiao CL, Hung YW, Shih TC and Bau DT: Contribution of DNA repair xeroderma pigmentosum group D genotypes to colorectal cancer risk in Taiwan. Anticancer Res 36: 1657-1663, 2016.

11 Bailey LB and Gregory JF, 3rd: Polymorphisms of methylenetetrahydrofolate reductase and other enzymes: metabolic significance, risks and impact on folate requirement. J Nutr 129: 919-922, 1999.

12 Knock E, Deng L, Wu Q, Leclerc D, Wang XL and Rozen R: Low dietary folate initiates intestinal tumors in mice, with altered expression of $\mathrm{G}_{2}-\mathrm{M}$ checkpoint regulators polo-like kinase 1 and cell division cycle 25c. Cancer Res 66: 10349-10356, 2006.

13 van der Put NM, Gabreels F, Stevens EM, Smeitink JA, Trijbels FJ, Eskes TK, van den Heuvel LP and Blom HJ: A second common mutation in the methylenetetrahydrofolate reductase gene: An additional risk factor for neural-tube defects? Am J Hum Genet 62: 1044-1051, 1998.

14 Robien K and Ulrich CM: 5,10-Methylenetetrahydrofolate reductase polymorphisms and leukemia risk: a HuGE minireview. Am J Epidemiol 157: 571-582, 2003.

15 Kang SS, Zhou J, Wong PW, Kowalisyn J and Strokosch G: Intermediate homocysteinemia: a thermolabile variant of methylenetetrahydrofolate reductase. Am J Hum Genet 43: 414421, 1988.

16 Homberger A, Linnebank $M$, Winter C, Willenbring $H$, Marquardt T, Harms E and Koch HG: Genomic structure and transcript variants of the human methylenetetrahydrofolate reductase gene. Eur J Hum Genet 8: 725-729, 2000.

17 Sohn KJ, Croxford R, Yates Z, Lucock M and Kim YI: Effect of the methylenetetrahydrofolate reductase $\mathrm{C} 677 \mathrm{~T}$ polymorphism on chemosensitivity of colon and breast cancer cells to 5-fluorouracil and methotrexate. J Natl Cancer Inst 96: 134-144, 2004.

$18 \mathrm{Yu} \mathrm{L}$ and Chen J: Association of MTHFR Ala222Val (rs1801133) polymorphism and breast cancer susceptibility: An update metaanalysis based on 51 research studies. Diagn Pathol 7: 171, 2012.

19 Huang CY, Chang WS, Shui HA, Hsieh YH, Loh CH, Wang HC, Ji HX, Hsiao CL, Hsu CM, Tsai CW and Bau DT: Evaluation of the contribution of methylenetetrahydrofolate reductase genotypes to Taiwan breast cancer. Anticancer Res 34: 4109-4115, 2014.

20 Tsai CW, Hsu CF, Tsai MH, Tsou YA, Hua CH, Chang WS, Lin $\mathrm{CC}$ and Bau DT: Methylenetetrahydrofolate reductase (MTHFR) genotype, smoking habit, metastasis and oral cancer in Taiwan. Anticancer Res 31: 2395-2399, 2011.
21 Jia J, Ma Z and Wu S: Positive association between MTHFR C677T polymorphism and oral cancer risk: a meta-analysis. Tumour Biol 35: 4943-4948, 2014.

22 Liu ZB, Wang LP, Shu J, Jin C and Lou ZX: Methylenetetrahydrofolate reductase $677 \mathrm{TT}$ genotype might be associated with an increased lung cancer risk in Asians. Gene 515: 214-219, 2013.

23 Wu HC, Chang CH, Tsai RY, Lin CH, Wang RF, Tsai CW, Chen $\mathrm{KB}$, Yao $\mathrm{CH}$, Chiu CF, Bau DT and Lin CC: Significant association of methylenetetrahydrofolate reductase single nucleotide polymorphisms with prostate cancer susceptibility in taiwan. Anticancer Res 30: 3573-3577, 2010.

24 Pei JS, Hsu CM, Tsai CW, Chang WS, Ji HX, Hsiao CL, Miao CE, Hsu YN and Bau DT: The association of methylenetetrahydrofolate reductase genotypes with the risk of childhood leukemia in Taiwan. PLoS One 10: e0119776, 2015.

$25 \mathrm{Hu}$ PS, Chang WS, Chou AK, Hsia NY, Hung YW, Lin CW, Wu CW, Huang CY, Wu MF, Liao CH, Tsai CW, Bau DT and Gong CL: The association of MMP-8 genotypes with pterygium. In Vivo 32: 41-46, 2018.

26 Pei JS, Chang WS, Hsu PC, Hung YW, Cheng SP, Tsai CW, Bau DT and Gong CL: The contribution of $M M P-8$ promoter genotypes to childhood leukemia. In Vivo 31: 1059-1064, 2017.

27 Liao CH, Chang WS, Hu PS, Wu HC, Hsu SW, Liu YF, Liu SP, Hung HS, Bau DT and Tsai CW: The contribution of $M M P-7$ promoter polymorphisms in renal cell carcinoma. In Vivo 31: 631-635, 2017.

28 Hung YW, Tsai CW, Wu CN, Shih LC, Chen YY, Liu YF, Hung HS, Shen MY, Chang WS and Bau DT: The contribution of matrix metalloproteinase- 8 promoter polymorphism to oral cancer susceptibility. In Vivo 31: 585-590, 2017.

29 Wu NC, Su SM, Lin TJ, Chin J, Hou CF, Yang JY, Liu WS and Chang LC: Methylenetetrahydrofolate reductase C677T and A1298C polymorphisms and fluorouracil-based treatment in Taiwan colorectal cancer. Anticancer Drugs 26: 888-893, 2015.

30 Jacques PF, Bostom AG, Williams RR, Ellison RC, Eckfeldt JH, Rosenberg IH, Selhub J and Rozen R: Relation between folate status, a common mutation in methylenetetrahydrofolate reductase, and plasma homocysteine concentrations. Circulation 93: 7-9, 1996.

31 Chen J, Giovannucci E, Kelsey K, Rimm EB, Stampfer MJ, Colditz GA, Spiegelman D, Willett WC and Hunter DJ: A methylenetetrahydrofolate reductase polymorphism and the risk of colorectal cancer. Cancer Res 56: 4862-4864, 1996.

32 Junker R, Kotthoff S, Vielhaber H, Halimeh S, Kosch A, Koch HG, Kassenbohmer R, Heineking B and Nowak-Gottl U: Infant methylenetetrahydrofolate reductase 677TT genotype is a risk factor for congenital heart disease. Cardiovasc Res 51: 251-254, 2001.

33 Yeh CC, Lai CY, Chang SN, Hsieh LL, Tang R, Sung FC and Lin YK: Polymorphisms of MTHFR C677T and A1298C associated with survival in patients with colorectal cancer treated with 5-fluorouracil-based chemotherapy. Int J Clin Oncol 22: 484-493, 2017.

34 Chiang FF, Huang SC, Wang HM, Chen FP and Huang YC: High serum folate might have a potential dual effect on risk of colorectal cancer. Clin Nutr 34: 986-990, 2015.

35 Shiao SP and Yu CH: Meta-prediction of MTHFR gene polymorphism mutations and associated risk for colorectal cancer. Biol Res Nurs 18: 357-369, 2016.

Received January 10, 2018

Revised February 3, 2018

Accepted February 5, 2018 